\title{
The Child Accident Prevention Trust (UK)
}

\author{
Louise Pankhurst
}

The Child Accident Prevention Trust (CAPT) is a voluntary organisation, a charity, established in 1981 by paediatricians to investigate the causes and prevention of accidents. The President of the CAPT is its founder, Dr Hugh Jackson, who remains active and in the vanguard of new ideas on prevention. Jane Asher, the Vice President, is not only a well known actress, but also a published expert on children's safety. CAPT's small core of staff is responsible to a board of 10 voluntary trustees. This board reflects a wide range of technical and medical skills, including a professor of child health, a director of a large national children's charity, a road safety expert, a consumer affairs media personality, a lawyer, and a financial management expert. The board and staff jointly determine the actions needed to meet objectives and find resources to carry out the work. The Patron is Her Royal Highness, the Princess of Wales.

CAPT also has a Professional Committee and Advisory Council that provide advice on research protocols and priorities. The former consists of nine child safety experts representing many disciplines. The latter includes 60 representatives of national organisations and government departments involved in injury prevention.

\section{Staff}

The Director is a sociologist and town planner with expertise on the built environment. She, along with Dr Hugh Jackson, maintains an interest in the social, cultural, and economic aspects of injury. Other senior staff include $\mathrm{Dr}$ Mike Hayes, whose $\mathrm{PhD}$ is in road accident research, and Dr Sara Levene, a paediatrician and expert in the relationship of child development to child safety. Dr Sharam Rahimi, with a doctorate in human information processing, is head of training and consultancy services. Dr Ellen Heptinstall whose $\mathrm{PhD}$ examined social factors in accident prevention, is coordinating a post-accident support project. Helen Richardson, with knowledge of training and networking, is responsible for training projects. Lesley Corner, a teacher, coordinates the Child Safety Week campaign. A press and information officer, Susan Pinckney, ensures the library is accessible to students and others, and prepares and disseminates factsheets and a regular newsletter, Child Safety Review. Rosie Mercer, with skills in information dissemination and data collection is developing CAPT's work in Northern Ireland. Other experts are brought in either as consultants, through CAPT's connec- tions, or through its committees. The work is ably supported by a small, hard working administrative team.

\section{Funding}

CAPT receives core funding from the Department of Health. Support for individual projects comes from a variety of other government departments, the European Commission, grant making trusts, and sponsorship. In addition the trust generates income from publishing, consultancy, and training services. In all cases, CAPT remains independent of its funders and publishes the truth as it sees it.

\section{Philosophy}

The trust combines an appreciation of the developing child with an understanding of the value of research. We believe that children are special because their environment is designed, built, managed, and provided for them by adults. Accordingly, children have little or no control over their world. Children are not viewed as small adults but as persons who need to be understood in their own terms. Their development and behaviour is generally predictable so that safety measures can be provided before they are required. Research enables useful measures and risk assessment techniques to be distinguished from gimmicks. Our strategy is to use research findings to target preventive actions at the most relevant or vulnerable groups.

Generally, work progresses in three phases: information gathering and research followed by the preparation of products recommended by the research (subject to funding) and finally, implementation, in the form of partnerships or alliances. This approach enables us to keep a narrow, targeted focus. CAPT does not see itself as a high profile, publicity orientated body because it does not believe such an approach works without well targeted interventions. We believe there is more to be gained by raising awareness of, say, burn prevention among the group most likely to be at risk than among the population as a whole. Another advantage is that funding can be sought for particular projects that correspond to the interests of funders.

\section{Approach}

When a project is funded, a steering group composed of volunteers is established to give advice and support. Members are brought in 
from such widely differing sectors as industry, government, the police, fire, or the medical professions to provide technical information. This is intended to ensure that the requirements of organisations that will ultimately be putting the work into effect are met. A sense of involvement and ownership of the work in hand is engendered in this way. This is particularly important when working with other voluntary organisations who bring with them valuable opportunities to tap into their networks in the community and access to volunteers. An additional benefit is the integration of child safety into other areas of care or service provision, thereby contributing to a more holistic approach.

Although it is both cost effective and secures penetration when other organisations include child safety in their policies, there is also a downside. For example, it is not always possible to secure adequate public recognition of the key role played by CAPT, or to maintain control over the direction of the work. Both issues are important because the timing and amount of funding for projects is grant aided, sponsored, or donated in proportion to the reputation of the 'lead' organisation. This reflects the publicity and recognition the funding body gains by association with the recipient.

Cost effective management policies are important because child safety work is significantly under resourced in comparison with many other child health issues and there is great competition for resources.

Working with government departments and statutory health and local authorities has become complicated because of changes in the organisation and funding of public services and the privatisation of many sectors and agencies. Voluntary organisations such as CAPT have adapted government's business ideas but this goes further than simply being businesslike and efficient. Steps have to be taken to persuade relevant bodies to include child safety in their service plans. The service specifications are then subject to competitive tendering involving either an internal market, private companies, or charitable providers. To what extent our freedom of operation will be compromised by these government inspired 'business' trends remains to be seen.

\section{Information dissemination}

An essential part of our work is research and the dissemination and promotion of research results to the audience most likely and able to act upon them. Publications include technical reports, such as those on in-car safety, the establishment of loan schemes for safety equipment, or low cost cycle helmets. We house a exceptional research library open to students and researchers and our information service produces a quarterly subscription newsletter giving news on regulations, policy, and safety activities.

\section{Research}

Examples of previous research include:
A study of coroners' records to assess the value of information about the circumstances of accidents recorded; a study of accidents to children while in hospital

- A feasibility study on a public access poisons information service for the UK

- Child deaths by falls on stairs

- The viability of a national child safety campaign

- The development of infant restraint loan schemes

\section{Current research includes:}

- An evaluation of local child accident prevention health alliances in two parts of the UK. This study examines how alliances work, how priorities are set, how local data are collected and used

- Hazardous substances. Research on lead poisoning has identified the need for information for parents

- The economic costs of accidents to health and local authorities, and the social costs to families, and society as a whole. These costs help justify investment in prevention and bring us closer to the personal tragedies

- The emotional effects of injuries on children and their families. Despite medical care, injuries can result in post-traumatic stress disorder. The present phase of this project involves reviewing the literature, determining the views of parents and children, and identifying post-accident support services

- Working children: almost one third of children under 16 years work-in shops, restaurants, agriculture, small factories, or on deliveries. While children gain experience and independence working, many suffer serious injuries or even death. We are investigating the steps required to minimise the possibility of these injuries or to enable the parties to carry out a risk assessment

\section{Meetings and workshops}

CAPT organises various meetings, ranging from formal lectures (often by visiting experts), to conferences-sometimes on an international scale jointly with organisations such as the European Consumer Safety Association (ECOSA) - to workshops, where greater individual participation can be achieved.

\section{Consultation and advice}

Our consultative and advisory role includes representation on a number of safety standards committees in the UK and Europe. We provide safety advice to members of the public, professionals, students, enforcement officers, and government departments. Information sheets on various topics, from burns and scalds, poisoning, pedestrian safety through to cot death and carbon monoxide poisoning, are made freely available. Training and consultancy is undertaken to the specification of contracting bodies and are an increasingly important way to promote safety and to raise income. 
An important aspect of the consultation role is responding to policy documents or proposals, from government, professional bodies, and political parties. Recent examples include a response to the UK government's deregulation initiative, which proposed a reduction in regulation and 'red tape' to reduce perceived pressure and restraint on business. CAPT responded to government proposals to introduce self regulation and risk assessment on fire precautions in the workplace and proposals regarding the provision of a national service for the coordination and development of children's play and to a national commission on violence to children. The opportunity to draw attention to child safety issues, and to provide evidence of the consequences for child safety during the process of making national policy, is an increasingly important role we intend to extend to European issues.

\section{Major programmes}

CAPT has taken the lead in the UK in a number of areas such as children's rights and safety, in-car safety, and the promotion of effective local campaigning. For example, an in-car safety programme called 'First Ride, Safe Ride', involved midwives and health visitors to promote the use of rear facing infant restraints. 'Every Ride a Safe Ride' is aimed at those able to give advice on in-car safety. We have been on the front line in promoting cycle helmet use and have produced guidelines on low cost cycle helmet schemes in schools as one of a series of guides to current practice.

CAPT believes that campaigns must be based on sound information in order to turn awareness into action. It is one thing to assess injuries or products and develop idealised solutions. It is another, more difficult, matter to find ways to make these solutions work. Some features of accidents are especially difficult. The well marked social gradient in accidental injury, and more dramatically so with accidental death, is one such issue. For example, up to five times more children die in house fires in social class $\mathrm{V}$ than in social class I. Solutions that work for affluent families may be inappropriate for poor families who care just as much about their children's safety but often have many more problems to contend with and little control over their domestic environment, for example, by being a tenant. Measures aimed at disadvantaged groups must be appropriate to their lives and acceptable to them. A number of projects address this issue of inequity.

In the UK, where homelessness is almost endemic due to a shortage of affordable family accommodation, it is estimated that over 100000 children live in substandard temporary accommodation. Accordingly, we have prepared guidelines for improving the safety of families living in temporary accommodation. A resource pack for interdisciplinary group working was produced and well received. Research on the building and design features of flats, covering stairs, balconies, lifts, and external areas have resulted in checklists for tenants' groups, housing managers, and local authority and private landlords. This work is an example of materials to empower people to act to reduce hazardous environments at a community level.

A further illustration of CAPT finding ways to enhance the skills of fieldworkers to put safety across at the grass roots level is the Approaches to Local Child Accident Prevention (ALCAP) project. This draws together information about who is doing what in child accident prevention, the activities they are undertaking, and where they are working. One outcome is a database linking workers in the same professions, people in the same geographical area, or groups tackling the same sorts of issues. A second outcome is a set of publications giving practical guidance on setting up local alliances and planning local programmes for monitoring and evaluation.

CAPT takes a special interest in the work of professionals such as health visitors who are in a position to build relationships with families. A training resource has been developed to improve health visitor skills in giving accident prevention advice. Children and families were consulted during the research phase of this project to gain insights into their perception of prevention. CAPT is also investigating the opportunities for prevention in the work of primary health care teams and environmental health departments.

As a voluntary organisation we are able to pioneer new methods of working. One such method being used to reach families who place their children in daycare or play facilities is 'cascade training'. CAPT has a national project for those with lead responsibility for training within a range of daycare and play organisations. These top trainers undertake to train their colleagues using CAPT training materials called 'Accident Prevention in Daycare and Play Settings' which are endorsed by the UK Department of Health. An additional resource called 'Keeping Kids Safe' is also used at the point in the cascade when daycare and play workers are in touch with parents. Keeping Kids Safe was extensively piloted with a wide cross section of families, including a group of mothers being held in Holloway Prison and traveller communities. This extensive testing and consultation was carried out to ensure that the level of literacy and imagery was acceptable to as wide a cross section of the public as possible.

A project has also been established in Northern Ireland to enhance child safety activity. Its essence is that it should be locally driven and respond to local need. Among its activities is the adaptation of a child safety house for use as an educational resource and information centre.

Of all the work aimed at the general population, the annual Child Safety Week is the most extensive and ambitious. For the last three years CAPT has set up a national alliance of government departments and relevant safety organisations to promote a UK wide week of action. Local activists were encouraged to use the week as a framework within which to target local actions. A campaign pack was developed and participants were able to join an interactive 
computer based network. A formal evaluation demonstrated that Child Safety Week provides a desirable focus for local practitioners and increases the priority given to child safety work by managers.

\section{Conclusion}

CAPT seeks to change policy and practices that stand in the way of reducing accident and risk to children and young people. To do that requires the capability to carry out quality research and development, an expert staff, a viable organisation, and willingness to engage in public debate. CAPT has these qualities and every endeavour will continue to be made to work nationally and at European and international level to save the lives of children.

\section{Further reading}

1 Secretary of State for Health. The health of the nation. A strategy for health in England. London: HMSO, 1992 (Cm 1986; £13.60.)

2 United Nations. Convention on the rights of the child. Geneva: Defence for Children International and Unicef, 1989.

3 Lansdown $G$, Newell $P$, eds. UK agenda for children. London: Children's Rights Development Unit, 1994. (£20.)

Purchasing a bicycle helmet in New Zealand: the genesis of a research study

I recently went shopping in Dunedin to purchase a new bicycle helmet. My objectives were to replace my current ill fitting helmet and to purchase a helmet that (a) my 'head sat in' as opposed to one which 'sat on top of my head'; (b) fitted me well, that is, had no excess forward or backward or left to right movement; and (c) complied with the New Zealand safety standard or better.

I had undertaken a similar task three or so years ago and was amazed at the ignorance of retailers and the misinformation frequently conveyed. Given all the publicity since then I had high expectations that the situation would have improved. I regret to say it had not. What follows is a summary of my casual observations after having visited six specialist bicycle shops.

There was only one retailer (shop A) who both measured my head circumference and then ensured the helmet met the fit guidelines of the Land Transport Safety authority. In two instances I was simply pointed in the direction of the helmets. No assistance was forthcoming.

A theme that emerged on several occasions was that by purchasing a very expensive helmet (for example over \$100) I was purchasing a great deal more protection and I owed myself that. Upon further inquiry it was apparent there was no basis for the claim other than 'dearer must be better'. There was one exception to this; a shop assistant pointed out that the helmet in question met a superior US safety standard (correct) and pointed to the markings to this effect. That helmet was offered to me on special for $\$ 150$. (I subsequently purchased the same model elsewhere for $\$ 80$ !)

In one shop where I demonstrated the excessive movement of the helmet on my head I was advised: 'they all do that!'

After visiting the sixth shop I purchased a helmet from shop A. I was however, not completely happy with my purchase. Although the helmet met the standard, and my 'head sat in it', I was unable to adjust its fiddly straps to reduce to an acceptable level the forward and rearward movement. I reasoned that some 'fiddling' at home would sort it out. No so! Despite repeated attempts I have been unable to get the helmet to fit correctly. If someone with my persistence and knowledge cannot get a helmet to fit, what hope has a child?

If my experience is typical, it might help explain why many cyclists in New Zealand are not wearing their helmets correctly. What this experience demonstrates is that injury interventions may not be realising their full potential simply because insufficient thought has been given to the barriers to their proper adoption.

JOHN LANGLEY

Injury Prevention Research Unit, Preventive and Social Medicine, University of Otago, PO Box 913, Dunedin, New Zealand 